\title{
THE
}

\section{The Instrumentalised User: Human, Computer, System}

Scott Kushner

University of Rhode Island, scottkushner@uri.edu

Follow this and additional works at: https://digitalcommons.uri.edu/com_facpubs

The University of Rhode Island Faculty have made this article openly available.

Please let us know how Open Access to this research benefits you.

This is a pre-publication author manuscript of the final, published article.

Terms of Use

This article is made available under the terms and conditions applicable towards Open Access

Policy Articles, as set forth in our Terms of Use.

Citation/Publisher Attribution

Scott Kushner (2020) The instrumentalised user: human, computer, system, Internet Histories, DOI: $10.1080 / 24701475.2020 .1810395$ 


\section{The instrumentalised user: Human, computer, system}

\section{Scott Kushner}

Department of Communication Studies, University of Rhode Island, Kingston, RI, USA

Scott Kushner

312 Davis Hall

10 Lippitt Rd.

Kingston, RI 02881 USA

$+1(401) 874-5223$

scottkushner@uri.edu

ORCID: 0000-0002-1361-252X

Scott Kushner is Assistant Professor of Communication Studies in the University of Rhode Island's

Harrington School of Communication and Media. This article is part of a larger project on the theory and history of lurking in networked computing environments. Other projects include a cultural history of the event ticket and work on the cultures of listening to popular music. His essays have appeared in venues including New Media \& Society, Space and Culture, Convergence, and First Monday.

Manuscript length: 8,192 words, inclusive of body text, notes, and references. 


\title{
The instrumentalised user: Human, computer, system
}

\author{
Humans who encounter social media platforms have a role to play. They are expected to \\ generate content, a demand starkly illustrated by a mid-2010s Facebook prompt: "Write \\ something." This essay recuperates the history of this role, the "instrumentalised user," \\ and traces its development from the mid-1960s to the present. Drawing on evidence from \\ scholarly texts in ergonomics, media studies, computer science, psychology, Human- \\ Computer Interaction, and political economy, the essay traces the instrumentalised user's \\ emergence from decades of efforts to characterise and problematise those actors who \\ encounter computing. Using Actor-Network Theory to show how humans and computing \\ machinery were imagined to work together, the essay reveals that social media's efforts to \\ extract labour from its users are the heirs to a recurring theme in computer and internet \\ history.
}

Keywords: user; human-computer interaction; system; labour

\section{Introduction: "Write something"}

At the top of Facebook's News Feed is a text box containing a line of greyed-out text. For several years in the mid-2010s, that text read: "Write something." One scholar described that prompt as "a solicitation of speech" (Morrison, 2014, p. 122). Others wrote that it was "taken up by users as a way to provide detailed context" (Witek \& Grettano, 2012, p. 252). Still others speculated that it "encourag[ed] member activity [...] and incite[d] creation and sharing of content" (Sörum \& Fuentes, 2017, p. 159). But more than a solicitation or a form of encouragement, "Write something" was an instruction, a command, and an ideology. This essay excavates that ideology's history, from mid-1960s media studies through contemporary social media, using a range of textual sources and appealing to Actor-Network Theory.

Facebook's instructions have changed over time. Technology writers watch the prompts on Facebook and other platforms for clues about "corporate strategy or user practice" (Morrison, 
2014, p. 128). But “Write something” exposed Facebook's operating logic, and it appeared both onscreen and on the wall at Facebook's Palo Alto headquarters (Fattal, 2012, pp. 934-935). Of all the prompts social platforms have rolled out, "Write something" was especially revealing, because it issued a naked order to the user. Neither a suggestion nor a question ("What's on your mind, Scott?" Facebook asks in August 2020), "Write something" was written in the imperative mood: do this.

The tacit assumption here is that people interacting with a social platform have a job description: writing something. But to write something (or to tell Facebook what's on one's mind, or to tell Twitter what's happening) or otherwise to produce content (by placing images on Instagram or videos on TikTok) is to participate in the ideology of social media. Participation can mean something as vast as "mak[ing] sense of collective forms of life," but it is more often experienced as "a formatted procedure" that produces "an attenuated, temporary feeling of personal contribution" (Kelty, 2019, p. 1). To "Write something" is, literally, to fill out a webform - but, also literally, to do so according to Facebook's terms, to which one has agreed, though likely without reading them (Obar \& Oeldorf-Hirsch, 2020). The writer might imagine a readership of friends and acquaintances, but "the frenetic participation in interpersonal interactivity tends to mask the underlying audience": the platforms themselves (Andrejevic, 2016, p. 201; cf. Fisher, 2015, pp. 384-385). The public-facing rhetoric of social platforms emphasises connection, sharing, and fun. It obscures the fact that users are also used. To "Write something" is to be drawn into a proscribed relationship with digital computing: it is to become a user.

Existing scholarship approaches the users of technological artefacts in overlapping —and sometimes contradictory—ways. Users are "configured," constructed by designers in 
contradistinction to those who devise, build, and maintain a technological artefact (Woolgar, 1991, 76-80). Users configure technology designers (Mackay et al., 2000, p. 739). Users are reflections of project teams that create systems (Oudshoorn et al., 2004, p. 53; Bardini \& Horvath, 1995, p. 41). Users, specifically computer "end users," "like computers because they get to get their work done," whereas programmers "like computers because they get to program" (Nardi, 1993, p. 5). Users have tightly constrained relationships with machines, "such that only certain forms of access/use are encouraged" (Woolgar, 1991, p. 89). Users radically repurpose machines, resulting "in changes to both the interpretation and design of an artifact" and the constitution of social identities (Kline \& Pinch, 1996, pp. 765, 767). Users are designers, producers, marketers, distributors, and technical support (Lindsay, 2003). Users replace what media studies calls "audiences," especially when they "cross from one device or source to another" (Picone, 2017, pp. 379, 381). Users are "not a monolithic or straightforward group" (Mackay et al., 2000, p. 738). Users are complicated.

Unifying this work is a concern with how the term "user" constructs a role: possibilities for action and experience, which are occupied when encountering technological artefacts. This essay adds to this tradition by arguing that the social media user derives from a specific notion of the computer user, which I call the instrumentalised user. ${ }^{1}$ This history casts the user as an information-processing entity that is paired with another information-processing entity, the digital computer, in service of a goal assigned jointly to both by some external agent. This instrumentalised user serves as a tacit foundation for contemporary social media platforms, which depend upon the coordination of user labour (to generate and process content) and

\footnotetext{
${ }^{1}$ I have chosen "instrumentalised" over "instrumental" to emphasise that this logic is imposed upon human users, rather than being some innate characteristic.
} 
networked computing (to analyse, predict, and channel human affect) in order to manage human attention and drive advertising revenues. The instrumentalised user is essential because social platform owners need a way to think about users as part of a larger system: not free agents, but components.

Actor-network theory offers tools to make sense of this sort of system. The ANT framework famously demands that human and nonhuman actors be understood through their interactions. ANT thinks systems as systems, resisting the idea that one actor is somehow more essential than another and insisting that a system element is an actor only if its actions "make a difference in the course of some other agent's action" (Latour, 2005, p. 71). ANT is especially helpful here because it provides a toolbox for the "tracing of associations" among users and computing machinery (Latour, 2005, p. 5).

This essay recuperates representations of relationships between human users and machines (often — but not always - digital computers) since the 1960s. The source materials are primarily scholarly texts from ergonomics, media studies, computer science, psychology, Human-Computer Interaction, and political economy, but they also include a novel and a how-to book. The narrative begins in the mid-1960s, when media studies emerged as a framework to understand automation. I'll mine resonances between Marshall McLuhan's media theory and the writings of one of his University of Toronto colleagues on industrial design, which will help anchor the idea that human users are actors in a technological system in broader intellectual currents. I'll then trace a second thread, concerning the interactions between humans and a specific machine: the digital computer. This thread passes through a 1970s text on humancomputer dialogues and a 1980s text that married psychology to computer science. A central question in both of these moments concerns the user's role. Next, I'll tie these two threads 
together by exploring the rise of Human-Computer Interaction research in the 1980s and '90s, a new discipline that complicated the user question. Finally, I'll bring this history to bear upon social media, explaining how "Write something" emerges from successive characterisations and problematisations of the instrumentalised user.

\section{Extensions}

After the Second World War, the idea that human users were part of a system was bound up in reckonings with automation and new media technologies. Scholars confronted new relationships between humans and machines, not least at the University of Toronto. McLuhan is often the star of Toronto narratives, but it is by reading McLuhan alongside a Toronto contemporary, the medical doctor and engineer Edward Llewellyn-Thomas, that an early approximation of the instrumentalised user materialises. ${ }^{2}$ In work on ergonomics, Llewellyn-Thomas (1965b) grappled with what humans could contribute in the age of automation: "Man [sic] has become less and less a source of energy," and "more a controller of machines. He does not dig ditcheshe processes data" (p. 19).

Llewellyn-Thomas (1965a) focused on the data-processing human, the "tool-making animal" (p. 11), because he saw shortcomings in the way designers were adapting to the automated world they were building. Although Llewellyn-Thomas thought that "man [was] one of the best general-purpose computers" (p. 13), he also thought humans had limitations. Design had failed by imagining that humans were manipulable: "Engineers," he wrote, "have a weakness for designing as though they could change men. In general, if you design an artifact or a system which requires man to change to fit into it you will probably damage him and you will

\footnotetext{
${ }^{2}$ As John Durham Peters (2015) notes: “One reads McLuhan for sparks” (p. 17).
} 
certainly make him less efficient. You must design to suit his physique, his natural capabilities, and to use them in the best way" (p. 12).

If Llewellyn-Thomas charged engineers with designing around humans, thinking about humans remained central to engineers' work. Engineers, for Llewellyn-Thomas (1965a), didn't build things - they built systems: "One could no longer think of a gun, a predictor, an aimer, an ammunition passer, and so on, but one had to think of the whole system. This system's concept has become more and more sophisticated and we have come to realise that in most of the situations in which man is placed he forms an element in a system" (p. 11).

The idea that pokes through the matériel is an assemblage of humans and machines, where each element has a role to play: humans process data, while machinery executes resultant decisions. This was not only a matter of war-making; it could be applied equally "to the housewife in her kitchen or to the woman with a sewing machine" (Llewellyn-Thomas, 1965a, p. 11) — or, presumably, to any form of gendered labour that Llewellyn-Thomas could conjure up. At the heart of this model is the notion that the human is a system element, but one that is less receptive to modification than machines.

In sketching his model, Llewellyn-Thomas (1965b) chooses terminology that draws parallels between humans and machines. The model is replete with black boxes ("one does not know exactly what happens inside 'black boxes', but one can measure what goes in and what comes out" (p. 19)). Eyes and ears are "specialist sense receptors, or transducers" (p. 20), and, as a whole, the human "acts as a sampling servo system, that is, he takes information about a static and instantaneous value and moves from one value to another in little jumps" (pp. 21-22). Later, reviewing humans' environmental limitations, Llewellyn-Thomas's language resembles a user's manual: extreme temperature and noise "degrade performance." Vibrations, too: “The 
human body has a natural vibration frequency of between three and six cycles per second, so if you are designing vehicles, try to avoid this particular frequency or your human riders will start to 'resonate"' (p. 22).

This model offers a helpful starting point for a history of the instrumentalised user for three reasons. First, it shows how a broader notion of use and users emerged in the mid-20th century, when mechanisation was ascendant, and the digital computer was entering collective consciousness. Although computers were uncommon, and few people imagined themselves as computer users, Llewellyn-Thomas was familiar with them. He was among a group of Toronto scientists and engineers who "test[ed] his hypotheses using computers" and other equipment (Marchand, 1998, pp. 151, 175).

Second, Llewellyn-Thomas's model reads as ANT foreshadowed. His focus on humans as one of several interdependent system components, rather than freestanding agents, prefigures ANT's fascination with actors ("If an actor is said to be an actor-network, it is first of all to underline that it represents the major source of uncertainty about the origin of action" (Latour, 2005, p. 46, emphasis in original)). Similarly, Llewellyn-Thomas's insistence that the human is as much a part of a system as a sewing machine or a machine gun evokes John Law's (1999) describing ANT as a theory that insists on being applied "ruthlessly to all materials" (p. 4). These are only resonances (Llewellyn-Thomas was an engineer and a doctor, not a social theorist), but Llewellyn-Thomas's ideas will resurface later (explicitly in Liam Bannon's work, discussed below).

Third, Llewellyn-Thomas was himself an actor in a network. He and McLuhan moved in the same Toronto circles. When McLuhan began developing his media theory, LlewellynThomas was an early member of McLuhan's Centre for Culture and Technology (Gordon, 1997, 
p. 195). Some years later, Llewellyn-Thomas wrote science fiction novels; McLuhan kept two in his library, signed by the author. ${ }^{3}$ One of them (Llewellyn, 1979) echoed Llewellyn-Thomas's claims about humans and machines: "To control a combat cutter one must solve ten differential equations simultaneously. That task is beyond even a computer" (p. 25). A few lines later, a core concept from McLuhan appears: "[A] Pilot's senses have to extend out into her machine" (Llewellyn, 1979, p. 25). This fictional moment reprises a passage in Llewellyn-Thomas's (1965b) work on aviation engineering: "the high speed aircraft becomes an extension of the pilot." He reasons that the aeroplane's instruments extend the pilot's senses and that the pilot "is seeing, feeling and hearing through the machine which can be considered almost a part of the pilot” (p. 19). The formulations echo McLuhan's (1964) understanding of media as “any extension of ourselves" (p. 7) — of either our sensorium or our ability to impose our will on the world. ${ }^{4}$

If Llewellyn-Thomas's human-machine systems were McLuhanesque, the Toronto colleagues' ideas diverge in a subtle manner that foreshadows a key point of contention in the history of the user. Despite his famous technological determinism, McLuhan (1964) imagined humans as the sovereign agents in their proximate encounters with media-technological objects: “all technologies are extensions of our physical and nervous systems to increase power and speed" (p. 90). Llewellyn-Thomas (1965a) is less clear regarding who is in charge: "We can now define a system as a collection of elements serving a common end and connected by a common information network" (p. 11). Llewellyn-Thomas's machines were paired with humans

\footnotetext{
${ }^{3}$ See the finding aid to the Marshall McLuhan Library Collection, p. 264, available at https://fisher.library.utoronto.ca/sites/fisher.library.utoronto.ca/files/mcluhanFA-june2014.pdf.

${ }^{4}$ This idea dates to the late 19th century (Logan, 2019, p. 1).
} 
by some other actor and assigned the task of changing the world, even in some small way: move through space, process information, harvest human attention. The human has a role, and engineers must ensure that "he is properly employed in terms of both his abilities and limitations" (Llewellyn-Thomas, 1965a, p. 13).

\section{Model Humans}

James Martin's Design of Man-Computer Dialogues, which arrived in 1973, was highly attuned to abilities and limitations. The central question that Martin sought to unravel was: "What functions should be performed by the man [sic], and what by the machine" (p. 309)? In a sense, Martin picks up where Llewellyn-Thomas left off, with a narrowed focus on the relationship between humans and computing machinery. In this section, I'll follow this narrower track to show how the thing that Llewellyn-Thomas had black-boxed—the human—was opened up for examination.

Despite the resonances with Llewellyn-Thomas's thought, Martin's question veers off in a different direction. The question of how to divide the work was never at issue in LlewellynThomas, but it is essential for Martin (1973), who frames the human-computer system as an assembly that must be fine-tuned: "The terminal or console operator, instead of being a peripheral consideration, will become the tail that wags the whole dog" (p. 3).

There lingers in Martin a bias toward humans, reminiscent of McLuhan's sovereign human. In Martin's system, one party is ultimately responsible to deliver the work product: "The computer is there to serve [the human user], to obtain information for him, and to help him do his job. The ease with which he communicates with it will determine the extent to which he uses it" (p. 3). Martin thus outlines how computers should communicate messages to human users and how programmers can best compose messages for screens or printouts so that users respond 
correctly: "A system with an unpolished dialogue may occasionally give a response that is invalid or confusing or causes the operator to take an incorrect action" (p. 504). The computing machine must "know" how to talk to its user.

Martin's (1973) user is sovereign, but still very much embedded in a system; programmers succeed by "[recognizing] the machine's limitations and then building into the system appropriate human capabilities," in order to produce "a judicious combination of man and machine" (p. 310). Bemoaning "an unfortunate tendency [in] the popular press [...] to overly anthropomorphise the computer" (p. 7), Martin articulated strategies to structure dialogues that would "take into account the shortcomings of both man and the computer" (p. 4). While computers offered "power and speed" (p. 310), humans had an aptitude for "slow but highly parallel and associative thinking" (p. 7).

If computer and human unite to accomplish a task, existing scholarship had a blind spot. By black-boxing human users, computer system designers could not fully understand — or effectively engineer-one half of their systems: "Increasingly in the next decade, man must become the prime focus of system design" (Martin, 1973, p. 3, emphasis in original). Martin's question about distributing the work was really about making sense of human users. A response would arrive ten years later.

In 1974, the year after Martin's Design of Man-Computer Dialogues appeared, Stuart Card, Thomas Moran, and Allen Newell launched the Applied Information-Processing Psychology Project at Xerox's Palo Alto Research Center. Their mandate was to develop an “applied psychology of human-computer interaction” (Card et al., 1983, p. ix) by melding psychology and computer science. Card and Moran trained under Newell at Carnegie-Mellon (Steier \& Mitchell, 2014, p. 433): Card's Ph.D. was in cognitive psychology, while Moran's was 
in computer science. All three scholars were affiliated with an interdisciplinary programme that blended the two fields, and Newell held appointments at Carnegie-Mellon in both areas. The Xerox PARC project, Card (2014) would later write, was conceived by Newell, "with Tom Moran and me as the workers." The idea was to address what Newell understood to be a shortcoming in computer science: "computer science had been very asymmetrical, with almost all effort going into the machine side. Newell's belief was that more work was due on the human side" (p. 260).

Card, Moran, and Newell thus set out to develop a theory of the computer user. They were responding to Martin's call to place the human at the heart of system design. Indeed, they cited Design of Man-Computer Dialogues in their 1983 book, The Psychology of HumanComputer Interaction, the culmination of their work at Xerox PARC.

"[T]he user," Card et al. (1983) write, "does not operate the computer, he [sic] communicates with it to accomplish a task" (p. 7). The term "user" describes a cognitive function. Even if users' bodies operate computers, it is the fact of communicating with the computer that makes them users: "The user and the computer engage in a communicative dialogue whose purpose is the accomplishment of some task." (p. 4). What Card et al. call "some task" is analogous to Llewellyn-Thomas's "common end," and their framing of use as dialogue echoes Martin's work. The contribution that Card et al. make amounts to some overdue work on "the human side."

This work takes the form of a 75-page chapter on the human brain, called "The Model Human Processor." Much like the computer, "the human mind is also an information-processing system, and a description in the same spirit can be given" (Card et al., 1983, p. 24). ${ }^{5}$ The

\footnotetext{
${ }^{5}$ This idea echoes Thomas Sheridan and William Ferrell's (1974) efforts to draw an "analogy
} 
possibility of describing human cognition in computer-like terms allows Card et al. to imagine the human as a system component that can be understood - and potentially modified. In the context of the Model Human Processor, retraining personnel becomes analogous to reprogramming: "with training or experience in doing the problem, the problem solver will acquire knowledge for [...] making it more efficient" (Card et al., 1983, p. 365). ${ }^{6}$

For Card et al., the mind's actual operations matter less than the possibility of predicting human brain performance. Indeed, they restrict their ambitions to "making approximate predictions of gross human behavior" (p. 24). Card et al. claim neither that human and machine cognition are identical nor that brains are simply computers. Instead, they argue that human brains and computers are similar, because both process information: "The description is approximate when applied to the human, intended to help us remember facts and predict usercomputer interaction rather than intended as a statement of what is actually in the head" (p. 24). ${ }^{7}$ The similarities take form as processes and logics: "The recognize-act cycle, analogous to the fetch-execute cycle of standard computers, is the basic quantum of cognitive processing” (p. 41).

between the performance of a complex engineering system and that of a human operator" (p. 3). Card et al. (1983) cite Sheridan and Ferrell. Newell had also explored the notion in Siewiorek, Bell \& Newell (1982).

${ }^{6}$ Card et al. (1983) do not suggest that training humans is easy, or even that it is the best option for optimizing systems. Their focus is on using knowledge of human cognition to inform interface design (p. 11). Nevertheless: "knowledge in cognitive psychology [...] is sufficiently advanced to allow the analysis and improvement of common mental tasks" (p. 91). Even if learning is slow (p. 363), there is a contrast with Llewellyn-Thomas's position, which understood human capacities as fixed.

${ }^{7}$ Two collaborators wrote retrospectively of Newell's dual fascination with brains and computers: "The strategy of simulating human thinking did not rest on any assumption of similarity between computer architectures and the architecture of the brain beyond the very general assumptions that both were physical symbol systems" (Bell \& Siewiorek, 2011, p. 93) 
As they unbox the human brain, they find an information processor that can be predicted and modelled.

For Card et al., the payoff comes in the "human-computer system," a bundle of digital and human information processing that is deployed to complete a task. The difference between the "human-computer system" and Llewellyn-Thomas's "man-machine system" lies in the use of cognitive science's emergent tools to examine the human mind. Cognitive science had been moving toward a computational model of the human brain for some time, propelled by "the invention of the programmable computer, and more importantly its precursor, the mathematical theory of computability," which authorised thinking of digital computers and humans together, because it "provides an appropriate conceptual apparatus for theories of the mind" (JohnsonLaird, 1988, pp. 7, 51).

The Model Human Processor represents an advance in the history of the instrumentalised user because it addresses the neglected "human side." In order to understand the associations among users and computers, Card et al. theorised how different stimuli provoked the human sensorium, how the brain's processing capacities allowed it to parse inputs, and how its corporeal actuators responded. In short, the Model Human Processor offers an Actor-Network Theorystyle explication of users, imagining both the human-computer system and the human brain as a network of associations to be traced: a set of actors, working in concert, each making a difference. Though it only amounts to guilt by association, ${ }^{8}$ when Card (1981) first published a paper on the Model Human Processor, two years before The Psychology of Human-Computer Interaction, the first text cited in the first paragraph (p. 301) was a book by Bruno Latour.

\footnotetext{
${ }^{8}$ Fitting, though, as Latour (2005) preferred "sociology of associations" to "actor-network theory" (p. 9).
} 
Still, something was missing from the Model Human Processor. The work Card et al. did at Xerox PARC helped shape a new disciplinary formation, a field that bears the same name as their book's title: Human-Computer Interaction, often known as HCI, whose branches include theoretical speculation about those interactions and pragmatic engineering of the interfaces that catalyse them. Card, Moran, and Newell would all become active in the HCI community. When the field's flagship conference, CHI, was first held, in 1982, Moran was listed as the author on four papers, while Card was an author on two. Newell was a keynote speaker at CHI in 1985; in 2001, Card and Moran were among the first group of inductees in the CHI Academy, a sort of disciplinary hall of fame. Though their ideas circulated readily in HCI's early days, the field quickly became intellectually and methodologically diverse, and some of the field's fiercest debates contested the cognitive approach's adequacy to the task of knowing users.

\section{Contesting the User}

In a generally positive review of The Psychology of Human-Computer Interaction, shortly after the book's publication, Ben Shneiderman (1984), who also gave a paper at that first CHI conference and would be an inaugural CHI Academy inductee alongside Card and Moran, expressed a reservation: "There is little concern for the user community and even less recognition of its diversity [...]. Differences in computing background, mathematical skills, gender, culture, cognitive styles, personality, motivation, etc. apparently do not merit discussion" (p. 240). If users were to be understood as people who communicated with computers, then understanding who those humans were would matter. Not only users' cognitive capacities, but also their identities, experiences, and interests were important.

As HCI emerged as a distinct discipline, it expanded its focus from the expert users with whom Card et al. concerned themselves to include those whom Jonathan Grudin (2017) called 
"discretionary users" (p. 41): people who used computing technology in the wide range of settings where their lives unspooled. These were the hobbyists who bought PCs in the 1980s and '90s, picked up personal data assistants around the turn of the millennium, and glued smartphones to their palms in the early 21 st century (Grudin, 2017, pp. 42-43). These were the people who came to know computers as machines for communication and entertainment, not calculations. And, as HCI took up the user question, these were people who were more than assorted sensors, processors, and actuators.

A steady current in the HCI literature recalibrated comparisons of humans and computers. Whereas Card et al. underlined similarities between humans and computers, subsequent HCI literature lingered on differences. Shneiderman made "the basic assertion that people are not machines and machines are not people" (Shneiderman \& Maes, 1997, p. 56). Liam Bannon (1991) similarly railed against approaches where "the human is [...] reduced to being another system component" (p. 27).

Bannon's position arrived in an influential essay that rejected an emphasis on human factors in design, preferring instead a focus on human actors. This discursive reorientation became shorthand for efforts to account for human users as active agents irreducible to machinery: "People are more than a sum of parts; be they information-processing subsystems or physiological systems, they have a set of values, goals, and beliefs about life and work" (p. 28).

This represents a sharp break from an intellectual lineage anchored in Llewellyn-Thomas and McLuhan's Toronto circle, Martin's computer dialogues, and the Model Human Processor advanced by Card et al. Bannon's human-computer assemblage was ultimately much vaster, as it acknowledged social, environmental, political, and cultural contexts. Whereas the tradition Bannon wrote against sought to imagine the user as a discrete piece of machinery, he imagined 
the user as deeply embedded.

It is thus notable that Bannon (1991, p. 25) appealed to Llewellyn-Thomas's (1965a) formulation, "Man is one of the best general-purpose computers available” (p. 13), in his essay's epigraph. At first blush, Bannon used Llewellyn-Thomas as a foil. Indeed, as Bannon unfolds his argument, he sketches just this sort of opposition: "Within the [Human Factors] approach, the human is often reduced to being another system component with certain characteristics, such as limited attention span, faulty memory, etc., that need to be factored into the design equation for the overall human-machine system." For Bannon, this approach is inadequate, because it obscures an essential truth about users and interface design: humans are complex, and that complexity must be accounted for. "Individual motivation, membership in a community of workers, and the importance of the setting in determining human action are just a few of the issues that are neglected" (pp. 27-28).

In arguing for "human actors," Bannon refuses to black-box human complexity. The imputation is that a construct like the Model Human Processor is an attempt to impose order on messy phenomena. Human relationships, associations, and identities cannot, for Bannon, be represented by mathematical computability. Rather than zeroing out human motivations, memberships, and communities, Bannon engages with their complexity-like an ANT scholar, he implies it is possible to "find order much better after having let the actors deploy the full range of controversies in which they are immersed" (Latour, 2005, p. 23).

It is in Llewellyn-Thomas that Bannon finds the seeds of a more nuanced user. His epigraph quotes further from Llewellyn-Thomas: "if one designs for man as a moron, one ends up with a system that requires a genius to maintain it." For Llewellyn-Thomas, this passage is an argument for immutable human traits. For Bannon, it's a way to align HCI with humans. 
Along similar lines, Bonnie Nardi (1996) insisted on the asymmetry of people and machines. Cognitive psychology offered only limited resources for understanding the human side of the computing equation, and Nardi and other scholars sought new approaches to HCI (Kuutti, 1996, p. 19). Writing of one potential approach, Nardi (1996) explained that "people are not reduced to 'nodes' or 'agents' in a system; 'information processing' is not seen as something to be modelled in the same way for people and machines" (p. 13). For Nardi, a human brain may process information, but it does so in a manner incommensurate with digital computing.

Still, insisting on users' humanity may be just another way to instrumentalise users. In a mid-'90s effort to unpack the rhetorical machinery of HCI, Geoff Cooper and John Bowers (1995) argue that "users are a necessary construct for HCI's legitimacy, in that they form a constituency awaiting representation" (p. 52). They trace a movement from the cognitive tradition (led by Card et al.) to a critical "second wave" (led by Bannon). Despite the divergences between the two, Cooper and Bowers (1995) emplot the legitimating function of the user as a unifying thread in HCI scholarship. Even when users are granted agency to act on their values, goals, and beliefs, the category of the user is still put to work. The discipline, they argue, relies upon its claim to have knowledge of users in order to authorise both its theorizing about interactions and its findings about the interfaces it strives to shape (p. 52). The user is at once "the constituency HCI claims to represent" (p. 50) and the justification for its existence.

More recently, even the notion that users should be at the centre of $\mathrm{HCI}$ research has been questioned. Eric P. S. Baumer and Jed Brubaker (2017) describe HCI's focus on the user as "myopic," claiming that HCI tends "to 'user-ify' people - transforming people into representations within our systems, interfaces, design practices, and discourse" (p. 6921). Humans interact with computers in a variety of ways, and the intentional, goal-orientated user 
that HCI privileges excludes many of them: those who rely on others to "use" computing machinery for them, as in the Global South (where literacy and computer knowledge are sometimes rare) and in the offices of the Global North (where the powerful have "delegates" who handle their email); or ambient computing scenarios, including "smart" thermostats and fast-food menu kiosks, which maintain no persistent profile of those who interact with them (pp. 6296-6297).

The Post-User discourse is part of a wave of scholarship, in HCI and beyond, on nonconforming user practices: lurking (Crawford, 2009, 2011; Kushner, 2016), leaving (Brubaker et al., 2016; Kushner, 2011), deactivating (Wagenknecht, 2018), and abstaining (Casemajor et al., 2015; Portwood-Stacer, 2012, 2013). In each instance, scholars explore various limit cases that dissolve connections between human and user. But the drive to distinguish between these two subject positions arrives only after the rise of social media makes the distinction confusing enough to require teasing out. As HCI enters middle age, it has succeeded in nuancing the notion of the user, but the instrumentalised user is alive and well. The social web has absorbed all of those complexities, paired them with computing, and sought to redirect them once more in service of an external task.

\section{Conclusion: The Persistence of the Instrumentalised User}

Facebook's "Write something" performs precisely this sort of redirection. It does not emerge fully formed, but rather descends from the half-century of history that winds through LlewellynThomas and McLuhan's Toronto, the Palo Alto of Card et al., and HCI's disciplinary maturation. It is in this redirection that this history comes to a resting place, at least for the time being. But how does it configure the user - and the relationship among users and networked computing? Facebook's demand that its user "Write something" responds to a question at the heart of 
Joshua Porter's (2008) book, Designing for the Social Web: “What do people have to do for us to be successful" (p. 26)? If that instruction is placed atop Facebook's News Feed and periodically revised by company managers, and if these revisions are tracked by journalists, this is all because one measure of Facebook's success is whether users put content in that box.

In order to get people to do what web designers need, Porter (2008) suggests that users' work be organised in terms of goals, activities, and tasks: "Goals are end conditions that people are striving for. Activities are the set of tasks that people do to achieve their goals" (p. 26). What follows is usability sleight-of-hand. After divining users' goals, designers develop activities to help users pursue those goals. Porter (2008) counsels his reader: "Try not to describe the activity in terms of you, the designer. The activity is not 'giving us money' or 'using our stuff.' These are simply byproducts (hopefully) of the activity itself' (p. 27).

The parenthetical "hopefully" speaks loudly; indeed, the terms could be reversed. From the designer's perspective, users' wants or needs are important only inasmuch as they align with fulfilling the platform's needs. Social platforms speak the liberatory language of user empowerment (Instagram: “A simple, fun $\&$ creative way to capture, edit $\&$ share photos, videos \& messages with friends \& family"; Snapchat: "Life's more fun when you live in the moment!"). But it is by aligning empowerment with instrumentalisation that Porter's designers can succeed. What forms might this take? Porter (2008) offers examples. "If we were Amazon, we might answer: 'purchasing goods."' This is straightforward enough: Amazon succeeds when it sells merchandise. "If we were Netflix, we might answer: "choosing movies to watch." This example is a bit more complex. Although Netflix was shifting from red envelopes to streaming video as Porter's book was published, the form of its success remained stable: Netflix needs users to find (not "choose") enough satisfactory content to justify the subscription cost. Porter's 
last example engages with the social web of his book's title and reveals the stakes: "If we were YouTube, we might answer: 'uploading videos"' (p. 26). With Amazon and Netflix, the thing that people must do is a form of consumption. With YouTube, it is a form of production. Of course, "uploading videos" is a close cousin to "Write something."

Porter revisits this logic when he compares the ways users are instrumentalised across different platforms. Here the terms shift. Amazon users are no longer buying goods, but rather "writing a product review." Netflix users are "rating a movie." The slippage is from consuming products to producing content. YouTube users, however, are still "uploading a video," which is displayed to other users ("YouTube interface, embedded in blogs"), who might "Favorite it, Report it, Embed it” (p. 129).

Why must YouTube users upload videos? Why must Facebook users write something? Why must social media users be instrumentalised? Because social media depends on its users collaborating with digital computing to complete "some task" (as Card et al. (1983) put it) or to pursue a "common end" (in Llewellyn-Thomas's (1965a) terms). It is necessary that both users and computers perform work in order to complete this task.

The work that social media users perform is one term in the equation developed by scholars working in the political economy of communication. This tradition was inaugurated by Dallas Smythe's (1977) claim that the product sold by “mass-produced, advertiser-supported communications" was "audiences and readerships" (p. 3). Audiences were valuable because, as they watched television (to catch scripted programmes, news broadcasts, or athletic competitions), they also watched advertisements, from which broadcasters derived their revenues. Sut Jhally and Bill Livant (1986) later called this "watching extra" (p. 126). In Porter's (2008) terms, viewers' satisfaction from watching sit-coms is (hopefully) a by-product 
of realizing broadcasters' goal of placing advertisements before "audiences with predictable specifications" (Smythe, 1977, p. 4). As part of a working relationship, users are called upon to perform free labour, "productive activities that are pleasurably embraced and at the same time often shamelessly exploited" (Terranova, 2000, p. 37).

Marc Andrejevic (2002) traces a key shift in the political economy of communication as turn-of-the-century interactive media increasingly placed viewers, readers, listeners, and users under surveillance: they are "recruited to participate in the labor of being watched [...] by subjecting the details of their daily lives to increasingly pervasive and comprehensive forms of high-tech monitoring" (p. 231). The things users buy, the places they go, the people the interact with, and the desires, dreams, hopes, and fears they reveal all become fodder for targeting advertisements.

But social media users also differ from television audiences because of their relationship to another of Smythe's key terms. Smythe (1977) described the "information, entertainment and 'educational' material transmitted to the audience" as "an inducement (gift, bribe or 'free lunch')" (p. 5). In media environments such as television, radio, and print journalism, the free lunch is provided by the media company: a broadcaster either produces or purchases content in hopes of attracting an audience with particular characteristics. This "free lunch" is then given away in exchange for the extra attention accorded to advertisements. In the social media environment, "platforms rely upon users to make free lunch for one another" (Kushner, 2016). The work of watching (Jhally \& Livant, 1986) begets the work of being watched (Andrejevic, 2002) begets the work of working. ${ }^{9}$

\footnotetext{
${ }^{9}$ Hesmondhalgh (2010) complicates this logic, arguing that while social media's leveraging of usergenerated content is appropriative of user labour (and therefore alienating), "complaints about free labour
} 
Networked computing can connect users, distribute content, and serve microtargeted advertising, but the system relies on humans to create content. The partnership is a response to the puzzle Martin (1973) framed for his readers: what different functions can humans and computers fulfil (p. 309)? The function human users fulfil is to fold in their "values, goals, and beliefs" (Bannon, 1991, p. 28), as well as their "differences in computing background, mathematical skills, gender, culture, cognitive styles, personality, motivation, etc." (Shneiderman, 1984, p. 240). When users write something, reveal what's on their mind, describe what's happening, or upload videos, images, or sound, they are responding to social platforms' demand that they incorporate the various things $\mathrm{HCI}$ researchers found lacking in cognitive approaches. Social media users translate the affective substance of everyday life into structured data that can be processed by digital computing in order to attract other users and keep everyone's attention focused on the platform.

It is a well-worn trope to suggest that "being a media 'audience' member is basically what people do continually" (Bird, 2011, p. 512), that all time is work time (Smythe, 1977; Fuchs, 2012), and that social platforms colonise the recesses of everyday life (Manzerolle, 2010, pp. 460-461). The notion of the instrumentalised user helps better explain this colonisation in two ways. First, it shows that this arrangement is not new in computer and internet history. The instrumentalised social media user's inheritance dates at least to mid-20th-century reckonings with automation. Second, it complicates political economic accounts of social media. Yes, human users are subject to exploitation by social platforms that monetise their attention, lives,

need to be linked to discussion of which kinds of free labour merit payment" (p. 278), especially if users derive some other benefit besides payment. It is possible that user and audience relationships to the "free lunch" are not dissimilar, but that the thing that induces extra attention in social media is precisely the pleasure of participation. 
and time: "networked sociality is the product" (Scholz, 2007). But their exploitation is possible because they are, in ANT terms, actors. Social media are, to use McLuhan and LlewellynThomas's formulation, extensions of humans' sociality, but this is at least in part because platforms instrumentalise users precisely by extending their social capacities. User labour is necessary to the functioning of the system because their actions "make a difference in the course of some other agent's action," namely digital computing, underlining the "uncertainty about the origin of the action" (Latour, 2005, p. 71, 46). Users and computing act in concert; the confusion of the origin stems from the coordination of the action by a platform.

\section{Acknowledgments}

The author thanks Ian Reyes and Justin Wyatt, who provided feedback on an early version of this essay, as well as generous audiences at the University of Rhode Island and the 2019 conference of the Reception Studies Society. Thoughtful critiques from two anonymous reviewers and the patient stewardship of the Internet Histories editorial team were instrumental in refining the arguments here.

\section{Disclosure statement}

No potential conflict of interest was reported by the author.

\section{References}

Andrejevic, M. (2002). The work of being watched: Interactive media and the exploitation of self-disclosure. Critical Studies in Mass Communication, 19(2), 230-248.

Andrejevic, M. (2016). The pacification of interactivity. In D. Barney, G. Coleman, C. Ross, J.

Sterne \& T. Tembeck (Eds.), The participatory condition in the digital age (pp. 187-206). 
Minneapolis, MN: University of Minnesota Press.

Bannon, L. J. (1991). From human factors to human actors: The role of psychology and humancomputer interaction studies in system design. In J. Greenbaum \& M. Kyng (Eds.), Design at work: Cooperative design of computer systems (pp. 25-44). Hillsdale, NJ: Lawrence Erlbaum.

Bardini, T., \& Horvath, A. T. (1995). The social construction of the personal computer user. Journal of Communication, 45(3), 40-65.

Baumer, E. P. S., \& Brubaker, J. R. (2017). Post-userism. CHI '17. Proceedings of the 2018 CHI conference on human factors in computing systems (pp. 6291-6303). Denver, CO: Association for Computing Machinery.

Bell, G., and Siewiorek, D. P. (2011). The book Computer Structures: Thoughts after 40 years. IEEE Annals of the History of Computing, 33(2), 89-95.

Bird, S. E. (2011). Are we all produsers now? Convergence and media audience practices. Cultural Studies, 25(4-5), 502-516.

Brubaker, J. R., Ananny, M., \& Crawford, K. (2016). Departing glances: A sociotechnical account of 'leaving' Grindr. New Media \& Society 18(3), 373-390.

Card, S. K. (1981). The model human processor: A model for making engineering calculations of human performance. Proceedings of the Human Factors Society, 25(1), 301-305.

Card, S. K. (2014). The human, the computer, the task, and their interaction-analytic models and user-centered design. In D. M. Steier \& T. M. Mitchell, T. M. (Eds.), Mind matters: A tribute to Allen Newell (pp. 259-312). New York, NY: Psychology Press.

Card, S. K., Moran, T. P., \& Newell, A. (1983). The psychology of human-computer interaction. Mahwah, NJ: Lawrence Erlbaum. 
Casemajor, N., Couture, S., Delfin, M., Goerzen, M., \& Delfanti, A. (2015). Non-participation in digital media: Toward a framework of mediated political action. Media, Culture \& Society 37(6), 850-866.

Cooper, G., \& Bowers, J. (1995). Representing the user: Notes on the disciplinary rhetoric of human-computer interaction. In P. J. Thomas (Ed.), The social and interactional dimensions of human-computer interfaces (pp. 48-66). Cambridge, UK: Cambridge University Press.

Crawford, K. (2009). Following you: Disciplines of listening in social media. Continuum $23(4), 525-535$.

Crawford, K. (2011). Listening, not lurking: The neglected form of participation. In H. Grief, L Hjorth \& A. Lasén (Eds.), Cultures of Participation (pp. 63-77). Berlin: Peter Lang.

Fattal, A. (2012). Facebook: Corporate hackers, a billion users, and the geo-politics of the “Social Graph.” Anthropological Quarterly 85(3), 927-955.

Fisher, A. W. (2015). User be used: Leveraging the play in the system. Discourse 36(3), 383399.

Fuchs, C. (2012). Dallas Smythe today: The audience commodity, the digital labour debate, Marxist political economy and critical theory. Prolegomena to a digital labour theory of value. Triple-C 10(2), 692-740.

Gordon, W. T. (1997). Marshall McLuhan: Escape into understanding. New York, NY: Basic.

Grudin, J. (2017). From tool to partner: The evolution of human-computer interaction. San Rafael, CA: Morgan \& Claypool.

Hesmondhalgh, D. (2010). User-generated content, free labour and the cultural industries. Ephemera, 10(3-4), 267-284. 
Jhally, S., \& Livant, B. (1986). Watching as working: The valorization of audience consciousness. Journal of Communication 36(3), 124-143.

Johnson-Laird, P. N. (1988). The computer and the mind: An introduction to cognitive science. Cambridge, MA: Harvard University Press.

Kelty, C. (2019). The participant: A century of participation in four stories. Chicago, IL: University of Chicago Press.

Kline, R., \& Pinch, T. (1996). Users as agents of technological change: The social construction of the automobile in the rural United States. Technology and Culture 37(4), 763-795.

Kushner, S. (2011). Virtually dead: blogospheric absence and the ethics of networked reading. The Communication Review 14(1), 24-45.

Kushner, S. (2016). Read only: The persistence of lurking in Web 2.0. First Monday, 21(6).

Latour, B. (2005). Reassembling the social: An introduction to actor-network theory. Oxford, UK: Oxford University Press

Kuutti, K. (1996). Activity theory as a potential framework for human-computer interaction research. In B. A. Nardi (Ed.), Context and consciousness: Activity theory and humancomputer interaction (pp. 17-44). Cambridge, MA: MIT Press.

Law, J. (1999). After ANT: Complexity, naming and topology. Sociological Review, 47(Suppl. 1), 1-14.

Lindsay, C. (2003). From the shadows: Users as designers, producers, marketers, distributors, and technical support. In N. Oudshoorn \& T. Pinch (Eds.), How users matter: The coconstruction of users and technology (pp. 29-50). Cambridge, MA: MIT Press.

Llewellyn, E. (1979). The Douglas convolution. New York, NY: DAW Books.

Llewellyn-Thomas, E. (1965a). Human factors in design. In M. Krampen (Ed.), Design and 
planning (pp. 11-14). Waterloo, ON: University of Waterloo Press.

Llewellyn-Thomas, E. (1965b). A model of man applied to design. In M. Krampen (Ed.), Design and planning (pp. 19-23). Waterloo, ON: University of Waterloo Press.

Logan, R. K. (2019). Understanding humans: The extensions of digital media. Information, 10(10), article 304.

Mackay, H., Carne, C., Beynon-Davies, P., \& Tudhope, D. (2000). Reconfiguring the user: Using rapid application development. Social Studies of Science 30(5), 737-757.

Manzerolle, V. (2010). Mobilizing the audience commodity: Digital labour in a wireless world. ephemra 10(3-4), 455-469.

Marchand, P. (1998). Marshall McLuhan: The medium and the messenger. Cambridge, MA: MIT Press.

Martin, J. (1973). Design of man-computer dialogues. Englewood Cliffs, NJ: Prentice-Hall. McLuhan, M. (1964). Understanding media: The extensions of man. Cambridge, MA: MIT Press.

Morrison, A. (2014). Facebook and coaxed affordances. In A. Poletti \& J. Rak (Eds.), Identity technologies: Constructing the self online (pp. 112-131). Madison, WI: University of Wisconsin Press.

Nardi, B. A. (1993). A small matter of programming: Perspectives on end user computing. Cambridge, MA: MIT Press.

Nardi, B. A. (1996). Activity and human computer interaction. In B. A. Nardi (Ed.), Context and consciousness: Activity theory and human-computer interaction (pp. 7-16). Cambridge, MA: MIT Press.

Obar, J. A., \& Oeldorf-Hirsch, A. (2020). The biggest lie on the internet: Ignoring the privacy 
policies and terms of service policies of social networking services. Information, Communication \& Society 23(1), 128-147.

Oudshoorn, N., Rommes, E., \& Stienstra, M. (2004). Configuring the user as everybody: Gender and design cultures in information and communication technologies. Science, Technology \& Human Values 29(1), 30-63.

Peters, J. D. (2015). The marvelous clouds: Toward a philosophy of elemental media. Chicago, IL: University of Chicago Press.

Picone, I. (2017). Conceptualizing media users across media: The case for 'media user/use' as analytical concepts. Convergence, 23(4), 378-390.

Porter, J. (2008). Designing for the social web. Berkeley, CA: New Riders.

Portwood-Stacer, L. (2012). Anti-consumption as tactical resistance: Anarchists, subculture, and activist strategy. Journal of Consumer Culture 12(1), 87-105.

Portwood-Stacer, L. (2013). Media refusal and conspicuous non-consumption: The performative and political dimensions of Facebook abstention. New Media \& Society 15(7), 1041-1057.

Scholz, T. (2007). What the MySpace generation should know about working for free. RePublic, http://web.archive.org/web/20070502020321/http://www.re-public.gr/en/?p=138.

Sheridan, T. B., and Ferrell, W. R. (1974). Man-machine systems: Information, control, and decision models of human performance. Cambridge, MA: MIT Press.

Shneiderman, B. (1984). [Review of the book The psychology of human computer interaction, by S. K. Card, T. P. Moran \& A. Newell]. Datamation, 30(1), 236-240.

Shneiderman, B., \& Maes, P. (1997). Direct manipulation vs interface agents. Interactions, $4(6), 42-61$. 
Siewiorek, D. P., Bell, C. G., and Newell, A. (1982). Computer structures: Principles and examples. New York, NY: McGraw-Hill.

Smythe, D. (1977). Communications: blindspot of Western Marxism. Canadian Journal of Political and Social Theory, 1(3), 1-27.

Sörum, N., \& Fuentes, C. (2017). "Write something”: The shaping of ethical consumption on Facebook. In F. Cochoy, J. Hagberg, M. Petersson McIntyre \& N. Sörum (Eds), Digitalizing consumption: How devices shape consumer culture (pp. 144-166). London, UK: Routledge.

Steier, D. M., \& Mitchell, T. M. (2014). Mind matters: A tribute to Allen Newell. New York, NY: Psychology Press.

Terranova, T. (2000). Free labor: Producing culture for the digital economy. Social Text, 18(2), $33-58$.

Wagenknecht, S. (2017). Beyond non-/use: The affected bystander and her escalation. New Media \& Society 20(7), 2235-2251.

Witek, D., \& Grettano, T. (2012). Information literacy on Facebook: An analysis. Reference Service Review, 20(2), 242-257.

Woolgar, S. (1991). Configuring the user: The case of usability trials. In J. Law (Ed.), A sociology of monsters: Essays on power, technology and domination (pp. 57-99). London: Routledge. 